\title{
RECHT ODER GEWALT? ZUM TODE SALVADOR ALLENDES*
}

\begin{abstract}
Diese Zeitschrift hat sich der Erforschung des Rechts in den überseeischen Staaten verschrieben. Sie will die Rolle aufzeigen, die das Recht in dem Prozeß der Anpassung dieser Staaten an die Verhältnisse unserer Zeit zu leisten vermag. Das besondere Problem der sogenannten Entwicklungsländer liegt darin, daß sie in einer Ordnung bestehen müssen, die sie selbst nicht mitgeprägt haben, eine Ordnung, die vielmehr zu einem guten Teil gegen ihre Interessen von den europäischen Staaten und deren Neugründungen in Nordamerika, Südamerika und Australien entwickelt worden ist. Unserer Überzeugung nach vermag das Recht in dieser Lage entscheidend zu einer wirklichen Modernisierung beizutragen. Nur eine sichere und gerechte Ordnung innerhalb der Entwicklungsländer, die von dem größten Teil der Bevölkerung getragen wird, kann Ausgangsbasis für eine aktive zukunftssichere Reform des internationalen Systems sein.
\end{abstract}

Effektivität des Wirtschaftssystems und internationale Unterstützung in einer Weltordnung, die sich weitgehend gerade gegen die Interessen Chiles richtet, durften nicht Maßstab für die Beurteilung der Politik Allendes sein. Vielmehr war entscheidend, ob das Vertrauen in die Möglichkeiten einer freien politischen Ordnung gestärkt und die Mitwirkung aller Betroffenen am politischen Prozeß gesichert wurde. Eine Regierung, die im eigenen Lande auf Polizeiterror und Unfreiheit ihre Macht gründet, ist ein schlechter Anwalt für die Beseitigung von Unterdrückung und Ausbeutung im internationalen Rahmen. Es kann dahinstehen, ob die Regierung Allende zu sehr auf die Macht des Rechts vertraute und es ihr "Fehler" war, nicht gegen die Verfassung, sondern mit ihr regieren zu wollen. Sie versuchte jedenfalls, erstmals mit den Zielen der Verfassung Ernst zu machen und gleiche Chancen für jeden zu schaffen. Das Militär hat seine Aufgabe, den Staat in der von der Verfassung gegebenen Gestalt zu schützen, aufgegeben und diesen Staat beseitigt. Das Chile von heute ist nicht mehr der Staat der Verfassung von 1925 in der Fassung von 1971. Dieses Chile ist ein neuer, ein verfassungsloser, ein rechtloser Staat.

Das Militär hat nicht „die Essenz der Verfassung“ gerettet, sondern nur die Privilegien einiger weniger. Die chilenische Verfassung enthielt einen ausgesprochen aktiven Grundrechtsteil, der den Rechten der Bürger entsprechende Gewährungspflichten des Staates gegenüberstellte. Die wenigen konnten Privilegien jedoch nur besitzen, weil sie den meisten Chilenen vorenthalten wurden. Sie besaßen ihre Privilegien mithin entgegen der Verfassung, so daß ihr Schutz auch nicht die Rettung der Verfassung sein konnte. Selbst ein offenkundiger Verfassungsbruch Allendes hätte das Vorgehen des Militärs nicht rechtfertigen können. Die bloße Behauptung, Allende habe die Verfassung verletzt, genügte dagegen schon Teilen der deutschen Presse, das brutale Vorgehen des Militärs zu rechtfertigen oder in einem milderen Licht erscheinen zu lassen.

Der Putsch in Chile bestürzt, weil in diesem Land das Militär traditionell verfassungsireundlich eingestellt war. Die jetzige Machtübernahme hat gezeigt, daß diese Verfassungstreue nicht der Einsicht in die Notwendigkeit rechtlich begründeter und damit geordneter Machtausübung entsprang, sondern nur deshalb mög-

\footnotetext{
* Dieser Beitrag stellt die Meinung des verantwortlichen Redakteurs, nicht eine offizielle Stellungnahme der an der Zeitschrift beteiligten Institute dar.
} 
lich war, weil die Verfassung das soziale Gefüge nicht beeinträchtigte, solange Bürgerliche an der Macht waren. Die Ereignisse in Chile haben aber noch eine andere Dimension. Der Kampf um eine gerechtere und bessere Ordnung, national wie international, wird jetzt noch weniger Chancen haben, mit Mitteln des Rechts und im Rahmen des Rechts geführt zu werden: Konservative können auf die Gefahren hinweisen, die die Gewährung von Freiheiten an Marxisten für die Wirtschaft und die internationale Stellung eines Landes birgt, linke Gruppen werden auf Chile zur Rechtfertigung eines militanten revolutionären Vorgehens verweisen und die Möglichkeit friedlicher Reform im Rahmen der verfassungsmäßigen Ordnung a priori ablehnen.

Wenn diese Zeitschrift trotz des Sieges der Gewalt über das Recht in Chile sich weiter für das Recht als einem tauglichen Mittel der Entwicklung zum Nutzen aller einsetzt, so geschieht das in der Hoffnung auf die Kraft rationaler Argumente gegenüber irrationalem Vorgehen. Was in Chile im September 1973 geschah, war zutiefst irrational, weil es Verhältnisse perpetuiert, die ihre Unfähigkeit, der Herausforderung unserer Zeit zu genügen, bereits bewiesen haben. Der Tod des gewählten Präsidenten Allende darf nicht zur Resignation führen, sondern muß Aufruf für die Wissenschaft sein, in dem Kampf um mehr Rationalität, um mehr Gerechtigkeit und damit um Frieden nicht nachzulassen, sondern ihn mutig und verstärkt fortzusetzen. Wer jetzt nachläßt in dem Bemühen, den besseren Argumenten zum Sieg zu verhelfen, handelt ebenso irrational und falsch wie die Militärs in Chile.

Henning von Wedel 